\title{
Synthesis and structural studies of $\mathrm{Na}_{2} \mathrm{O}-\mathrm{ZnO}-\mathrm{ZnF}_{2}-\mathrm{B}_{2} \mathrm{O}_{3}$ oxyfluoride glasses
}

\author{
SHANTALA D PATIL, V M JALI* and R V ANAVEKAR ${ }^{\dagger}$ \\ Department of Physics, Gulbarga University, Gulbarga 585 106, India \\ ${ }^{\dagger}$ Department of Physics, Bangalore University, Bangalore 560 056, India
}

MS received 8 July 2007

\begin{abstract}
This paper describes the synthesis and spectroscopic studies of the glass system, $20 \mathrm{Na}_{2} \mathrm{O}-(20-x)$ $\mathrm{ZnO}-x \mathrm{ZnF}_{2}-60 \mathrm{~B}_{2} \mathrm{O}_{3}(x=0,5,10,15,20)$, prepared by melt quenching method. The analyses of DSC and XRD did not show the crystallinity of the glass sample. ${ }^{11} \mathrm{~B}$ MAS-NMR shows the presence of sharp peak around $-14 \mathrm{ppm}$. From the IR studies, the broadening of the peak around $1200-1400$ and $800-1100 \mathrm{~cm}^{-1}$ shows the presence of mixed linkages like $\mathrm{B}-\mathrm{O}-\mathrm{B}, \mathrm{B}-\mathrm{O}-\mathrm{Zn}$ in the network.
\end{abstract}

Keywords. Borate glasses; oxyfluoride glasses; glass structure; MAS-NMR; IR.

\section{Introduction}

Oxyfluoride glasses are promising host glasses for optical applications because of their excellent optical properties, high refractive index, low dispersion and good transparency in the UV and IR regions. These glasses also possess good chemical and thermal stability as well (Sidebottom et al 1997). Oxyfluoride glasses can be formed in various glass matrices such as $\mathrm{SiO}_{2}, \mathrm{TeO}_{2}, \mathrm{P}_{2} \mathrm{O}_{5}, \mathrm{~B}_{2} \mathrm{O}_{3}$ etc. Among all these, oxyfluoride glasses formed with $\mathrm{B}_{2} \mathrm{O}_{3}$ shows interesting behaviour because of the unique structure of $\mathrm{B}_{2} \mathrm{O}_{3}$.

$\mathrm{B}_{2} \mathrm{O}_{3}$ is one of the most common glass formers and is present in almost all commercially important glasses and it is often used as a dielectric material. Borate glasses can be formed over a wide range of modifier concentration at relatively lower melting temperatures (Pye et al 1978). In borate glasses, $\mathrm{B}_{2} \mathrm{O}_{3}$ is a basic glass former because of its higher bond strength, lower cation size and smaller heat of fusion. Therefore, the structural investigations of boron in these glasses are one of the most attractive points of borate glass formation and related doped systems. In the borate glasses, $\mathrm{B}^{3+}$ ions are triangularly co-ordinated by oxygen atoms and triangle units are corner bonded in a random configuration. The ${ }^{11} \mathrm{~B}$ MAS NMR investigation (Greenblatt and Bray 1967; Kim and Bray 1974; Prabhakar et al 1990) and the IR (Krogh-Moe 1965; Kamitsos et al 1987b; Kamitsos and Chryssikos 1991) studies were important in identifying several borate groups consisting of boron-oxygen triangles and tetrahedra which form the glass network at various modification levels. It is known

*Author for correspondence (vmjali@rediffmail.com) that in alkali modified borate glasses, up to $33.3 \mathrm{~mol} \%$ of $\mathrm{Na}_{2} \mathrm{O}$, there is continuous formation of $\mathrm{BO}_{3} \rightarrow \mathrm{BO}_{4}$ units and further increase in the alkali leads to reconversion of $\mathrm{BO}_{4} \rightarrow \mathrm{BO}_{3}$ with non-bridging oxygen. $\mathrm{PbO}$ and $\mathrm{ZnO}$ can enter the glass network as a network former and also as a network modifier (Veeranna Gowda and Anavekar 2004). Due to this the structure of glass is expected to be different from that of alkali borate glasses (Kim and Bray 1974; Munia et al 1999). In the present study, we report the synthesis and structural studies of $\mathrm{Na}_{2} \mathrm{O}-\mathrm{ZnO}-\mathrm{ZnF}_{2}-$ $\mathrm{B}_{2} \mathrm{O}_{3}$ oxyfluoride glasses and study the role of intersubstitution of $\mathrm{ZnO}$ by $\mathrm{ZnF}_{2}$.

\section{Experimental}

\subsection{Materials and methods}

A series of five glasses were synthesized having the general formula, $20 \mathrm{Na}_{2} \mathrm{O}-(20-x) \mathrm{ZnO}-x \mathrm{ZnF}_{2}-60 \mathrm{~B}_{2} \mathrm{O}_{3}(x=0,5$, $10,15,20)$, BNZF. Glasses were prepared by mixing together the appropriate weights of analar grade chemicals, $\mathrm{Na}_{2} \mathrm{CO}_{3}, \mathrm{ZnO}, \mathrm{ZnF}_{2}$ and $\mathrm{H}_{3} \mathrm{BO}_{3}$. The mixture was taken in a porcelain crucible and melted in an electric furnace at $1200^{\circ} \mathrm{C}$ to get a homogeneous melt. Different pieces of glasses with dimension $1 \times 1 \times 1 \mathrm{~cm}$ were obtained by quenching the melt between two copper blocks.

The amorphous nature of glasses was confirmed using X-ray diffractometer (Philips, PW1050/37) by employing $\mathrm{CuK}_{\alpha}$ radiation. The X-ray diffractogram did not show any sharp peaks, a characteristic of amorphous nature. The samples were crushed to powder and ${ }^{11} \mathrm{~B}$ MAS-NMR was recorded with a MSL-300 solid state high resolution spectrometer operating at $96 \cdot 28 \mathrm{MHz}$. The chemical shift 
values were recorded with respect to resonance signal of $\mathrm{BF}_{3} \mathrm{Et}_{2} \mathrm{O}$. The IR spectroscopic measurements were carried out in the range $400-1600 \mathrm{~cm}^{-1}$ using 'Perkin Elmer spectrum 1' in KBr media. All NMR/IR spectra were recorded at room temperature. All the glasses exhibited characteristic glass transition temperature and varied systematically as a function of alkali/divalent oxide concentration. The variation of $T_{\mathrm{g}}$ was determined using differential scanning calorimeter (Modulated DSC 2820) with small pieces of the samples in the temperature range $95-550^{\circ} \mathrm{C}$. The density of the glass samples were measured by Archimedes principle using benzene as an immersion liquid (density, $\rho=0.879 \mathrm{~g} / \mathrm{cc}$ ).

\section{Results and discussion}

\subsection{Density}

Figure 1 shows the variation of density as a function of $\mathrm{ZnF}_{2}$ concentration. As one can see from the figure the intersubstitution of $\mathrm{ZnO}$ by $\mathrm{ZnF}_{2}$ leads to an increase in the density (from $2 \mathrm{~g} / \mathrm{cc}$ to $3.4 \mathrm{~g} / \mathrm{cc}$ ) when $20 \mathrm{ZnO}$ is replaced by $20 \mathrm{ZnF}_{2}$. However, in the intermediate composition one can see that density fluctuates between 2.46 and $4.25 \mathrm{~g} / \mathrm{cc}$. This behaviour could probably be due to structural origin resulting from intersubstitution of $\mathrm{ZnO}$ by $\mathrm{ZnF}_{2}$ and it is described again in the later sections.

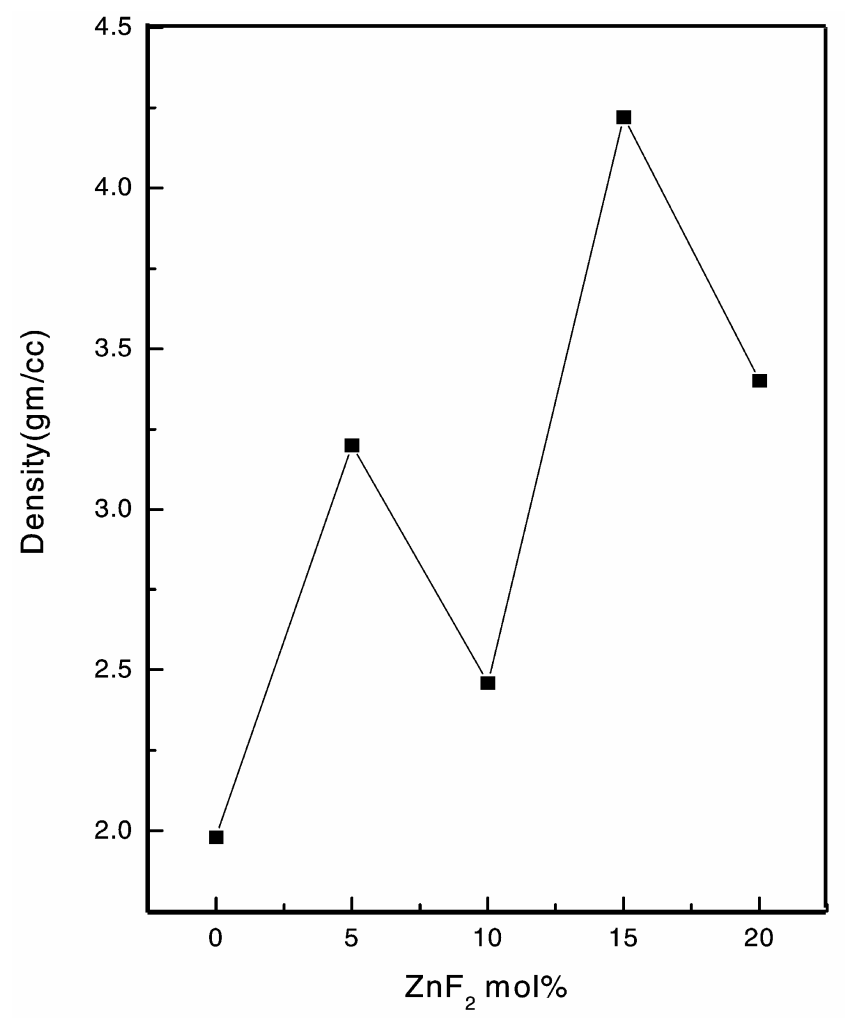

Figure 1. Variation of density with $\mathrm{ZnF}_{2} \mathrm{~mol} \%$.

\subsection{Differential scanning calorimetry}

Figure 2 shows the variation of glass transition temperature, $T_{\mathrm{g}}$, with $\mathrm{ZnF}_{2} \mathrm{~mol} \%$. In general, $T_{\mathrm{g}}$ is found to decrease with $\mathrm{ZnF}_{2}$ concentration. A decrease in $T_{\mathrm{g}}$ is a manifestation of the degradation of the glass network. This is because of the bigger size of $\mathrm{ZnF}_{2}$ than $\mathrm{ZnO}$ that leads to open structure resulting in a decrease of $T_{\mathrm{g}}$.

\section{$3.3{ }^{11} B M A S-N M R$}

${ }^{11}$ B MAS-NMR spectra of BNZF glass series are shown in figure 3 . The spectra reveals the presence of a sharp resonance peak at around $-14 \mathrm{ppm}$ (with respect to resonance signal of $\mathrm{BF}_{3} \mathrm{Et}_{2} \mathrm{O}$ ), which arises from boron atom in four coordination $\left[\mathrm{BO}_{4 / 2}\right]^{-}$. There is a split peak at the base of all the $\left[\mathrm{BO}_{4 / 2}\right]^{-}$signals which arises from boron atoms in $\left[\mathrm{BO}_{3 / 2}\right]^{0}$ coordination (Silver and Bray 1958: Bray 1985: Zhong and Bray 1989: Prabhakar et al 1992; Muthupari and Rao 1994). We have also examined variation of the fraction, $\mathrm{N}_{4}\left[\mathrm{~N}_{4}=\mathrm{B}_{4} / \mathrm{B}_{3}+\mathrm{B}_{4}\right]$ of boron atoms in $\left[\mathrm{BO}_{4}\right]$ units by finding area under the $\left[\mathrm{BO}_{4 / 2}\right]^{-}$and $\left[\mathrm{BO}_{3 / 2}\right]^{0}$ peaks (Muniya et al 1999).

Figure 4 shows the variation of $\mathrm{N}_{4}$ as a function of $\mathrm{ZnF}_{2}$ concentration. As can be seen from the figure, the $\mathrm{N}_{4}$ values do not vary systematically with intersubstitution of $\mathrm{ZnO}$ by $\mathrm{ZnF}_{2}$. However, the values of $\mathrm{N}_{4}$ are well below the diborate composition $\left(\mathrm{N}_{4} \approx 0 \cdot 5\right)$. Further, the

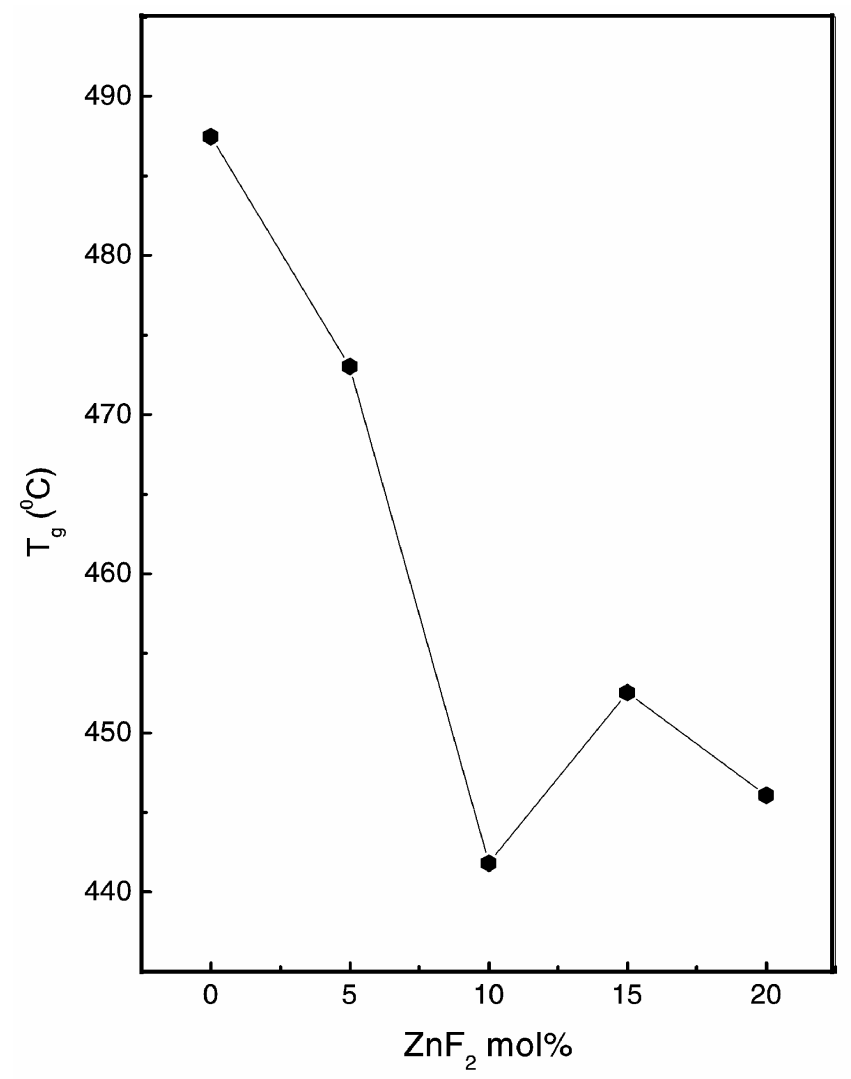

Figure 2. Variation of $T_{\mathrm{g}}$ with $\mathrm{ZnF}_{2} \mathrm{~mol} \%$. 
$\mathrm{N}_{4}$ values of $\mathrm{ZnF}_{2}$ free glasses are higher than those glasses containing $\mathrm{ZnF}_{2}$. This is likely due to the dual role of $\mathrm{Zn}^{2+}$ as former and modifier. The dual role of $\mathrm{Zn}^{2+}$ is also reflected in the density variation as a function of $\mathrm{ZnF}_{2}$ concentration.

\section{$3.4 \quad I R$}

Infrared spectra of the BNZF glass series are shown in figure 5. IR spectra consists of three strong absorption regions. The vibrations in the region between 1200 and $1400 \mathrm{~cm}^{-1}$ arises from borate units in which the boron atom is connected to three oxygens, $\left[\mathrm{BO}_{3 / 2}\right]^{0}$ and the broadening in this region is due to the mixed linkages present. The response in the region between 800 and $1100 \mathrm{~cm}^{-1}$ is due to boron atom in tetrahedral oxygen coordination $\left[\mathrm{BO}_{4 / 2}\right]^{-}$units. The $\mathrm{B}-\mathrm{O}-\mathrm{B}$ bending vibrations manifest in the lower frequency region between 600 and $800 \mathrm{~cm}^{-1}$ (Krogh-Moe 1965; Selvaraj and Rao 1984; Kamitsos et al 1987a). The relative intensities of the peak also undergo significant changes as $\mathrm{ZnF}_{2}$ concentration increases. The broadening of the peaks in the region

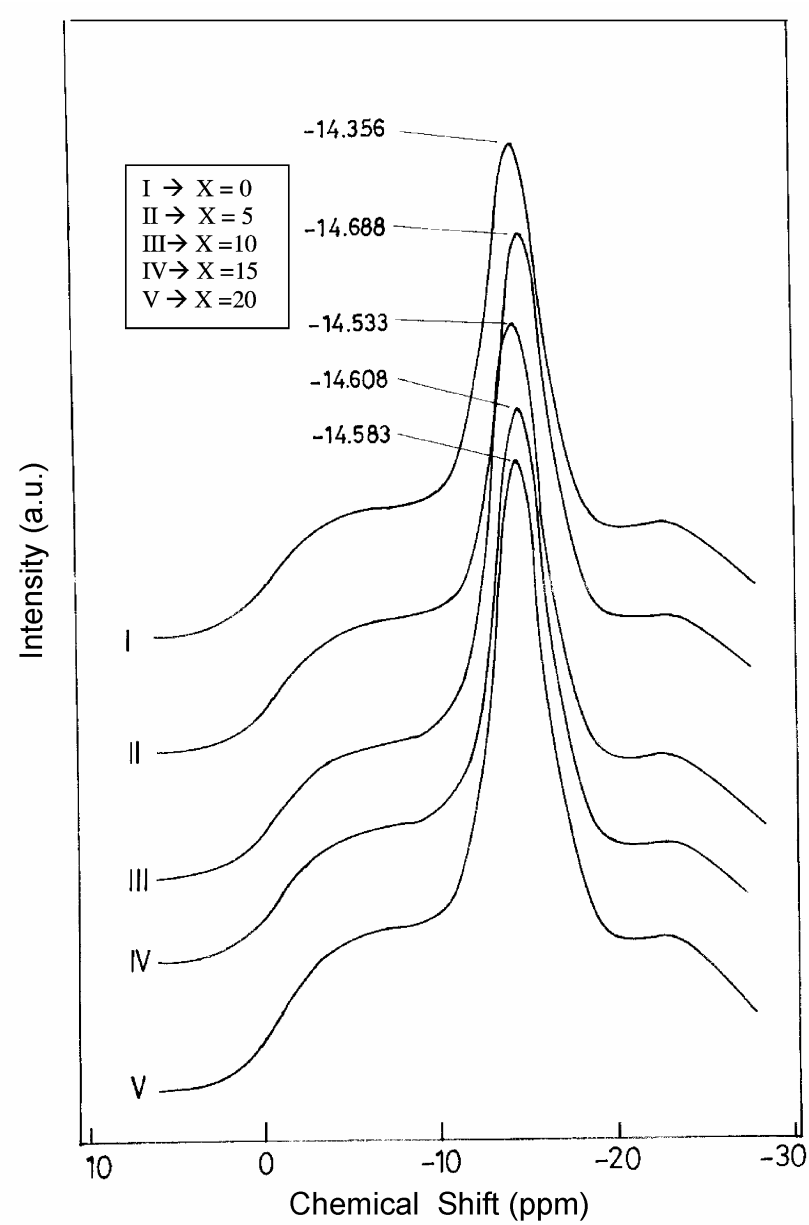

Figure 3. ${ }^{11}$ B MAS NMR spectra of BNZF glass system.

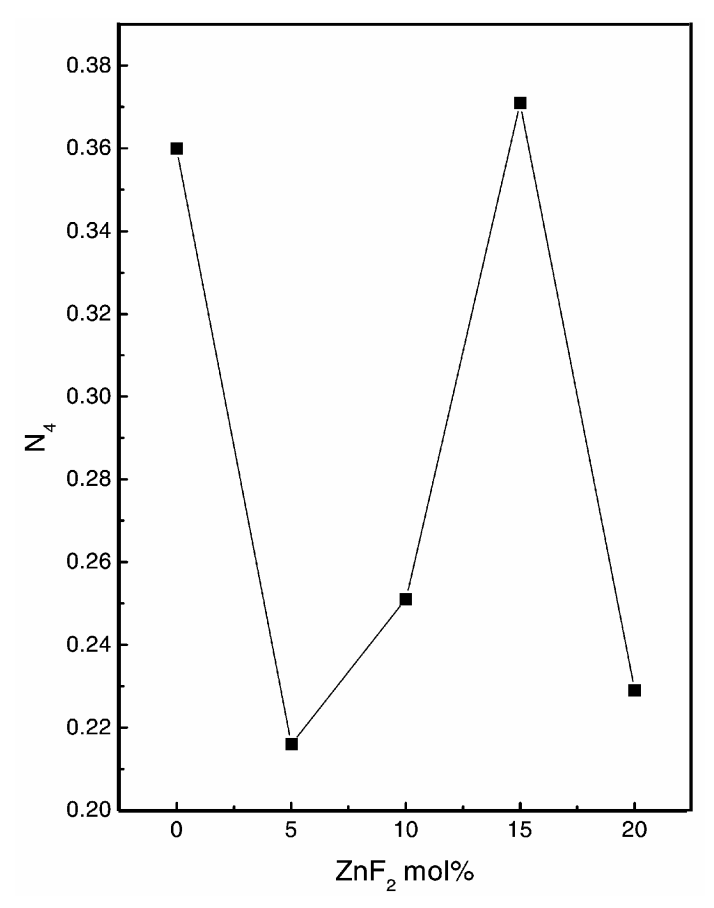

Figure 4. Variation of $\mathrm{N}_{4}$ with $\mathrm{ZnF}_{2} \mathrm{~mol} \%$.

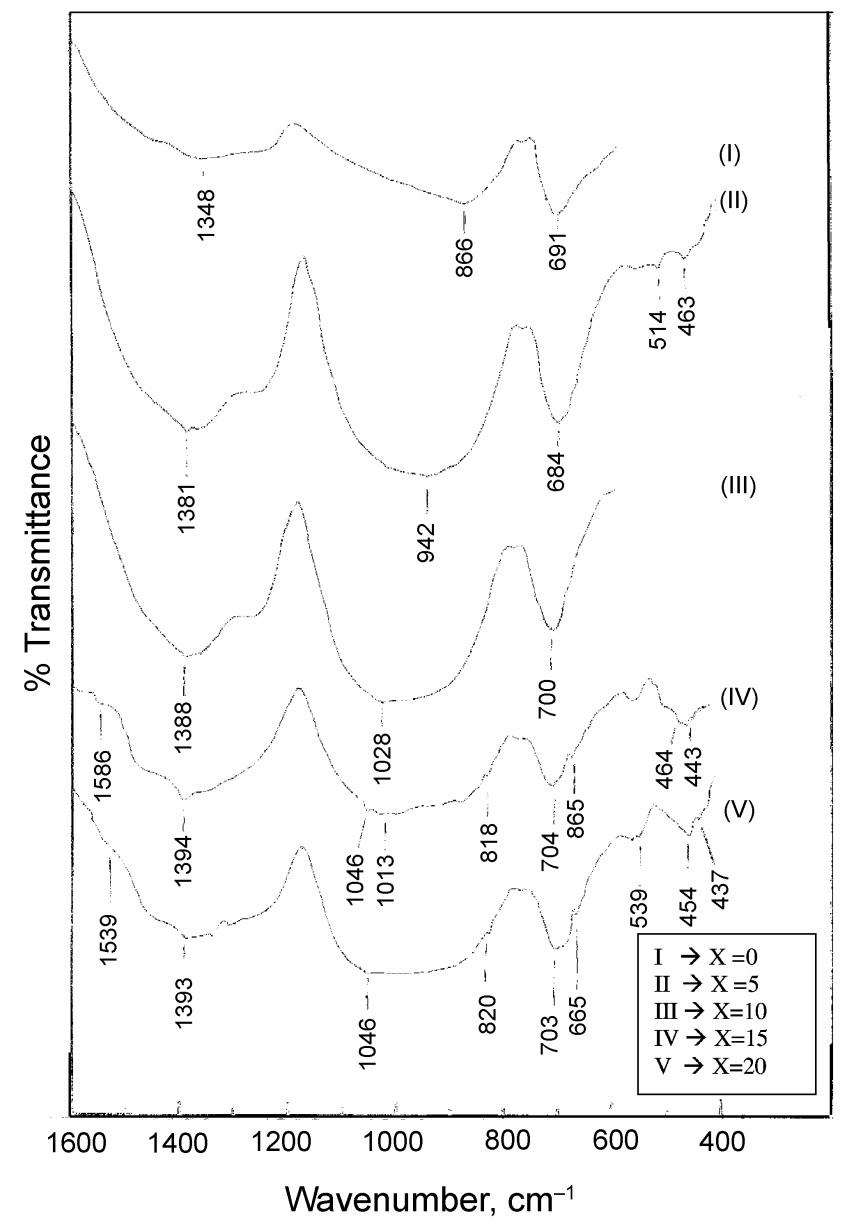

Figure 5. IR spectra of BNZF glass system. 
$1200-1400 \mathrm{~cm}^{-1}$ and $800-1100 \mathrm{~cm}^{-1}$ strongly indicates the presence of mixed bonding such as $\mathrm{B}-\mathrm{O}-\mathrm{B}$ and $\mathrm{B}-\mathrm{O}-$ $\mathrm{Zn}$. This observation is consistent with the variation of $\mathrm{N}_{4}$ values.

\section{Conclusions}

${ }^{11} \mathrm{~B}$ MAS-NMR, IR and DSC studies on $\mathrm{Na}_{2} \mathrm{O}-\mathrm{ZnO}-$ $\mathrm{ZnF}_{2}-\mathrm{B}_{2} \mathrm{O}_{3}$ glass system have been carried out to ascertain the role of $\mathrm{Zn}^{2+}$ ion in these glasses. Analysis of ${ }^{11} \mathrm{~B}$ MAS-NMR indicates the dual role of $\mathrm{Zn}^{2+}$ as former and modifier. IR spectra indicate the presence of mixed linkages like $\mathrm{B}-\mathrm{O}-\mathrm{B}$ and $\mathrm{B}-\mathrm{O}-\mathrm{Zn}$. The glass structure has been confirmed by XRD and DSC measurements.

\section{References}

Bray P J 1985 J. Non-Cryst. Solids 7529

Greenblatt S and Bray P J 1967 Phys. Chem. Glasses 8213

Kamitsos E I and Chryssikos G D 1991 J. Mol. Struct. 2471
Kamitsos E I, Karakassides M A and Chryssikoss G D 1987a Phys. Chem. Glasses 28203

Kamitsos E I, Karakassides M A and Chryssikoss G D 1987b J. Phys. Chem. 911073

Kim K S and Bray P J 1974 Phys. Chem. Glasses 1547

Krogh-Moe J 1965 Phys. Chem. Glasses 646

Munia Ganguly, Harish Bhat M and Rao K J 1999 Mater. Res. Bull. 341757

Muthupari S and Rao K J 1994 J. Phys. Chem. 982646

Prabhakar S, Rao K J and Rao C N R 1990 Proc. R. Soc. (London) A429 1

Prabhakar S, Rao K J and Rao C N R 1992 Eur. J. Solid State Inorg. Chem. 2995

Pye L D, Frechette V D and Kriedel N J 1978 Borate glasses: structure properties and applications (New York: Plenum Press)

Selvaraj U and Rao K J 1984 Spectrochim. Acta A40 1081

Sidebottom D L, Green P F and Brow R K 1997 J. Non-Cryst. Solids 222354

Silver A H and Bray P J 1958 J. Chem. Phys. 29984

Veeranna Gowda V C and Anavekar R V 2004 Bull. Mater. Sci. 27199

Zhong J and Bray P J 1989 J. Non-Cryst. Solids 11167 